\title{
Socio-economic differences in disability by age in sub-Saharan Africa: A cross-national study using the World Health Survey
}

\author{
Yentéma Onadja ${ }^{1}$ \\ Simona Bignami \\ Maria-Victoria Zunzunegui
}

\begin{abstract}
This study aims to examine the relationship between socio-economic status (as measured by education) and multiple disability measures among adults in eighteen sub-Saharan African countries, and to determine whether the strength of this relationship varies across age groups. The analysis uses data drawn from the 2002-04 World Health Survey. The findings indicate that low education is positively associated with poor functional health, and the functional health gap between educational levels increases across age groups. These findings suggest that in sub-Saharan African countries, the under-educated are less successful in postponing disability to later ages.
\end{abstract}

Keywords: socio-economic inequality, education, disability, functional health, sub-Saharan Africa

\section{Résumé}

Cette étude examine la relation entre le niveau d'éducation et les incapacités parmi les adultes dans 18 pays d'Afrique subsaharienne, et détermine si cette relation varie selon les groupes d'âge. L'analyse a utilisé les données de l'enquête mondiale de santé 2002-2004. Nos résultats indiquent que le manque d'éducation était positivement associé à des niveaux plus élevés d'incapacités, et le différentiel d'état de santé fonctionnelle entre les différents niveaux d'éducation augmentait entre les groupes d'âges. Ces résultats suggèrent qu'en Afrique subsaharienne, les individus faiblement éduqués ont moins de succès dans le report de l'incapacité dans la vieillesse.

Mots-clés : inégalités socioéconomiques, éducation, incapacités, santé fonctionnelle, Afrique subsaharienne

\section{Introduction}

\section{Background}

Lower socio-economic status (SES) has been shown to be related positively to poorer health among many populations in various social contexts (Adler et al. 1994; Eikemo et al. 2008; Feinstein 1993; Hosseinpoor et al. 2013; Marmot et al. 1997; von dem Knesebeck et al. 2006). This relationship appears robust across multiple indicators of both SES (for example, education, income, occupation, and wealth) and health (mortality, chronic diseases, disability, and self-rated health) (Beckett 2000; Dupre 2007; Eikemo et al. 2008; Hosseinpoor et al. 2012b, 2013; House et al. 1994; Kitagawa and Hauser 1973; Lauderdale 2001; Prus 2007; Robert and House 1996; Ross and Wu 1996; von dem Knesebeck et al. 2006). The robustness and virtual universality of the SES-

1. Principal and corresponding author: Yentéma Onadja, Institut Supérieur des Sciences de la Population (ISSP), Université Ouaga I Pr Joseph Ki-Zerbo, 03 BP 7118 Ouagadougou 03, Ouagadougou, Burkina Faso; email: yonadja@issp.bf. Coauthors: Simona Bignami, Département de démographie, and Maria-Victoria Zunzunegui, Département de médecine sociale et préventive, Université de Montréal. 
health relationship have increased recognition of its central place in efforts to understand and improve overall population health around the world (Herd et al. 2007).

Prior research has provided good theoretical insights into the mechanisms behind the relationship between measures of SES (especially education) and health. Education is seen as a fundamental social cause of health and illness (Link and Phelan 1995). For example, education is thought to improve health by providing not only economic resources but also psychosocial resources, such as personal control, social support, coping skills, and problem-solving abilities, as well as knowledge of health risks (Link and Phelan 1995; Mirowsky and Ross 2003; Ross and Wu 1995). People with lower education tend to have lower occupational status and income, and thus may be: unable to afford adequate health care, limited in terms of access to healthy food, and subject to living in less healthful environments and unhealthy housing conditions associated with a higher likelihood of illness and disease (Herd et al. 2007). Moreover, poor coping resources (such as personal control and problem-solving abilities), low social support, chronic stressors (such as relationship and family problems, financial stress), and negative life events are more common among persons with lower education, and these factors may significantly contribute to a greater number of health problems for poorly educated people (Lantz et al. 2005; Link and Phelan 1995; Turner et al. 1995). Finally, individuals with lower education are less likely to engage in healthpromoting behaviours such as good nutrition, physical activity, utilization of preventive and therapeutic health care, abstaining from smoking, moderation in alcohol consumption, and maintaining a healthy weight (Lantz et al. 1998; Link and Phelan 1995; Mirowsky and Ross 2003).

Despite the vast amount of literature on the relationship between SES and health, most of the research has been conducted in Western countries. In non-Western settings, the majority of studies that have examined this issue, with a few exceptions (Chen et al. 2010; Hosseinpoor et al. 2012b, 2013; Lowry and Xie 2009), have focused mainly on Asian, Latin American, and Caribbean countries and on older people (Beydoun and Popkin 2005; Rosero-Bixby and Dow 2009; Smith and Goldman 2007; Zimmer 2008; Zimmer and Amornsirisomboon 2001). These studies generally show a more erratic and weaker relationship between measures of SES and health than in Western countries (Beydoun and Popkin 2005; Rosero-Bixby and Dow 2009; Smith and Goldman 2007; Zimmer 2008; Zimmer and Amornsirisomboon 2001). In sub-Saharan Africa, the general subject of the SEShealth relationship has been broached only to a limited extent, and demographic and epidemiological literature has examined SES differentials in infant, child, and maternal health (Alvares et al. 2009; Caldwell 1986; Desai and Alva 1998; Soares 2007). Given that most of the existing studies have focused specifically on certain age groups, their results represent a truncated examination of the SES-health relationship, and also they do not address possible variations in the effects of SES on health covering a broad range of age, from early adulthood to very old ages. In the developed world, the empirical evidence on age differences in the relationship between SES and health is conflicting, and much remains unknown about whether these differences increase, decrease, or remain stable across age groups (Leopold and Engelhartdt 2013).

Therefore, the age gradient in the relationship between SES and health is still largely an open question. This issue is currently discussed in the literature in terms of three contrasting theoretical hypotheses: the cumulative disadvantage bypothesis, the age-as-leveller hypothesis, and the status maintenance bypothesis (Corna 2013; Leopold and Engelhartdt 2013; O'Rand and Henretta 1999). The cumulative disadvantage hypothesis suggests that socioeconomic differences in health continue to increase with age, due to the fact that the effects of initial disadvantages in SES accumulate with age to produce wide health disparities between socio-economic groups in later life (Lynch 2003; Ross and Wu 1996). Biological research also shows that compensatory mechanisms of the human organism may inhibit health decline until the age of 30 or 40 even if people experience unfavourable risk health factors (Power and Hertzman 1997; Power et al. 1999).

The age-as-leveller hypothesis, on the other hand, posits that the size of the SES-health relationship increases from young age to middle age and then decreases in old age (House et al. 1994), suggesting that age acts as a levelling force, which shrinks the health gap by SES in later life (Herd 2006). One explanation for this narrowing of health inequalities by SES at older ages may be later-life reductions in socio-economic differences in exposure to psychosocial and behavioural risk factors, as well as in the risk factors' effect on health (House et al. 2005; House et al. 1994). Another explanation is that over age, changes in health become more 
closely related to age than to any other predictor, and thus the health effects of SES may diminish with age (House et al. 2005; House et al. 1994). However, a major explanation for why health differentials by SES narrow in later life may be mortality selection, which biases downwards the "true" SES-health relationship at older ages (Lynch 2003; Willson et al. 2007). Mortality selection occurs when lower-SES people experience higher rates of mortality at younger ages compared to their higher-SES counterparts, leaving in old age a lower-SES group of robust survivors relative to the higher-SES subpopulation (Beckett 2000; Dupre 2007; Lynch 2003; Willson et al. 2007).

Finally, the status maintenance hypothesis proposes that the effect of SES on health remains rather stable irrespective of age (O’Rand and Henretta 1999), suggesting that social positions that individuals attain in early adulthood do not change considerably in later life. As a result, the health gap between different socio-economic groups is expected to remain constant across their life span (Leopold and Engelhartdt 2013).

To date, empirical research has found evidence for all three potential types of age gradient in the SEShealth relationship mentioned above. For example, using data for US adults, an increase in the strength of the SES-health relationship across the life course has been found for physical functioning by education level (Ross and Wu 1996), physical impairment by education and income (Kim and Durden 2007), and physical illness by income (Aneshensel et al. 1984). Moreover, some studies conducted in the developing world tend to support these findings (Chen et al. 2010; Lowry and Xie 2009). In contrast, a decrease in the size of the relationship between SES and health outcomes in old age, consistent with the age-as-leveller, has been found in the US for chronic conditions and functional limitations by education (Beckett 2000; Herd 2006; House et al. 1994), mortality by education (Elo and Preston 1996), and activity limitations by poverty status (Newacheck et al. 1980). Furthermore, studies conducted in European societies with strong social welfare policies for people of all ages support a constant effect of SES on health over the life course, consistent with the status maintenance hypothesis (Marmot and Fuhrer 2004; Rostad et al. 2009; Schöllgen et al. 2010).

In sum, previous research, conducted almost exclusively in Western countries, has documented a positive robust relationship between low SES and poor health, although there is a debate as to whether this relationship increases, decreases, or remains stable with age. Given the ambiguity of the extant literature, we cannot predict with confidence whether SES differentials in health will change or remain constant across age. Thus, more empirical evidence on the age trends of health inequalities by SES is needed-especially in other different social contexts like sub-Saharan Africa - to test the plausibility of the three competing theoretical hypotheses. Furthermore, a close examination of the relationship between SES and health across age groups in sub-Saharan African countries has the potential to identify mechanisms that can be targeted by policy programs in order to help postpone physical and mental health problems for people at low and high socio-economic levels in these settings, although it is important to bear in mind that the intervening mechanisms may change over historical time and require constant monitoring (Link and Phelan 1995).

\section{Study objectives}

The general objective of the present study is to contribute to our understanding of the general patterns of socio-economic differences in disability in sub-Saharan Africa. Using data from the World Health Survey (WHS) conducted in 2002-04 by the World Health Organization (WHO) (Üstün et al. 2003), this article aims to: (1) examine the relationship between SES and disability among adults aged 18 years and older in eighteen sub-Saharan African countries (Burkina Faso, Chad, Comoros, Congo, Côte d'Ivoire, Ethiopia, Ghana, Kenya, Malawi, Mali, Mauritania, Mauritius, Namibia, Senegal, South Africa, Swaziland, Zambia, and Zimbabwe); and (2) determine whether the strength of this relationship varies between the age groups.

In 2003 (the year most of the surveys were conducted), apart from Mauritius, which was an upper-middleincome country, all the other countries under study were low- and lower-middle-income countries (World Bank 2005). In addition, in all but three of the countries under study (Mauritius, Namibia, and South Africa), there is an important lack of social welfare policies for sub-Saharan African adults, especially older persons (National Research Council 2006). 
To address our research questions, this study relies on one key measure of SES—education level—and difficulties in eight core functional domains (mobility, self-care, pain and discomfort, cognition, interpersonal activities, vision, sleep and energy, and affect) developed by the WHO (Salomon et al. 2003). Although methodological challenges pertaining to the comparability of health status data across populations are likely to exist, previous research has shown that the WHO functional domains are highly consistent across countries (Üstün et al. 2003). By conducting our analyses separately for each of the functional domains, we highlight the heterogeneity of the age trends in education-related inequality for different disability measures.

\section{Methods}

\section{Study population and sampling}

This study uses data from the World Health Survey (WHS), which was conducted by the WHO in 2002-04 in seventy countries throughout the world (Üstün et al. 2003). The WHS was designed to use standardized modules and instruments for collecting cross-sectionally comparable data on health status and health service coverage for populations from six world regions (Üstün et al. 2003). In each participant country, the WHS was designed to produce a nationally representative sample of non-institutionalized men and women aged 18 years and older. This study includes 67,461 adults (18 years and older) living in the eighteen sub-Saharan African countries that have participated in the WHS: Burkina Faso, Chad, Comoros, Congo, Côte d'Ivoire, Ethiopia, Ghana, Kenya, Malawi, Mali, Mauritius, Mauritania, Namibia, Senegal, South Africa, Swaziland, Zambia, and Zimbabwe.

Within each country, a multi-stage stratified random cluster sampling strategy was used to select households. Lists of households were obtained from population registries, voter lists, manual enumeration, or other methods. Each member of the household was listed by the household informant. Within each household, an adult aged 18 years and older was randomly selected using a Kish table to complete the survey. Response rates were good, with the household response rate ranging from 54 per cent in Swaziland to 99 per cent in Burkina Faso, and the individual response rate ranged from 64 per cent in Congo to more than 85 per cent in the vast majority of countries studied. To adjust for the population distribution represented by the United Nations Statistical Division ${ }^{2}$ and also non-response, post-stratification corrections were made to the sampling weights (Moussavi et al. 2007). Additional information about the WHS sample and survey methodology is available on the WHS website. ${ }^{3}$

\section{Variables}

\section{Outcome variables}

The WHS participants aged 18 years and older were asked to rate the degree of difficulty they had experienced in each of the eight functional domains in the previous thirty days. The response categories were: $1=$ no difficulty, 2 =mild difficulty, 3 =moderate difficulty, 4 =severe difficulty, and 5 =extreme difficulty/cannot do. In this study, the outcome variable is the dichotomy poor functional health (comprising the functional domain responses "moderate," "severe," or "extreme/cannot do") vs. good functional health (comprising the functional domain responses "none" or "mild"). This binary outcome variable was created for each functional domain.

\section{Explanatory variables}

Main explanatory variables: socio-economic status measures

We use education as the key measure of SES because of its various qualities. Education later shapes the other indicators of SES, such as occupational status, income, and wealth (Liberatos et al. 1988). In addition,

2. http://unstats.un.org/unsd/default.htm.

3. http://www.who.int/healthinfo/survey/en/index.html. 
causal ordering between education and disability in adulthood may be readily interpretable as the effect of SES on disability and not vice-versa, because education is generally completed some time in late adolescence or early adulthood, making it among the least susceptible of all measures of SES to reverse causality (House et al. 1994). The direction of the relationship between income and disability, on the other hand, is not as clear because income may decline in adulthood to the extent that disability impairs work performance. Furthermore, measuring individual income in sub-Saharan African contexts can be problematic, especially in settings where a significant proportion of the population is still engaged in subsistence agriculture (National Research Council 2006). Concerning household wealth, as indicated by Ferguson and colleagues (2003), there is an important issue of cut-point shift when assets are used to construct the wealth index. Indeed, there are measurement error and comparability issues for the wealth index. Therefore, it is not as clear about what the relationship between the wealth index and functional health is really measuring. In addition, household wealth in terms of possessions of basic household assets has not always been a good predictor of consumption per adult (Montgomery et al. 2000). For all these reasons, we chose only education as a measure of SES in this study. Education is used as a categorical variable with four categories (no formal schooling, primary school, secondary school, and high school or above), but also as a continuous variable (i.e., number of years of schooling) for some of the analyses.

Other explanatory variables: socio-demographic

The socio-demographic variables considered as covariates are: respondent's sex (male vs. female), age, marital status, place of residence (rural vs. urban), and country of residence. Sex is strongly associated with both education and disability, with women having lower education and reporting higher levels of disability compared to men (Onadja et al. 2013). We code age at the time of the WHS interview as a categorical variable with six categories: 18-29, 30-39, 40-49, 50-59, 60-69, and 70+ years. Marital status is coded as: never married, married/cohabiting, and separated/divorced/widowed. Country of residence is a categorical variable with eighteen categories, and its introduction into the regression models allow us to control for country-fixed effects. Country-fixed estimations control for unobserved characteristics that are commonly shared by all individuals in a given country.

\section{Statistical analysis}

We begin by examining unadjusted bivariate associations between education level and measures of disability using pooled data from all the eighteen sub-Saharan African countries under study. We then use logistic regression models to estimate the associations of each measure of disability with education level, controlling for sex, age, marital status, place, and country-fixed effects. In the third step, we estimate odds ratios reflecting the change in the odds of poor functional health with every one-year increase in schooling by age group. The final step of the analysis consists of examining the age variations in the associations between education level and each measure of disability. Therefore, we add interaction terms between age and education level to the logistic regression models. The estimated coefficients for interaction terms obtained from these models allow us to calculate average predicted probabilities of each binary outcome variable for each education level across multiple age groups, while holding constant all socio-demographic factors. We present (as graphical representations) the predicted probabilities of poor functional health for the lowest- and highest-educated persons by age group. This analytical strategy enables us to see if differences in disability between these two educational levels are significant for each age group and whether they vary between the age groups. Due to the complex sampling strategy used to collect the WHS data, all models are estimated using the Huber/White estimator of variance in Stata. All analyses are weighted using the sampling weights that reflect each country's population distribution in such a way that if the sample size for two given countries is the same (but the population sizes of the countries are different), more weight is given to the country with higher population when calculating pooled estimates. 


\section{Results}

\section{Prevalence of reporting poor functional health}

Table 1 shows relative prevalence of poor functional health across the eight core functional domains considered, overall and for each country separately. The overall prevalence of poor functional health is lowest for self-care (8 per cent) and highest for pain and discomfort (24.3 per cent). The prevalence of each of the eight functional domains is highest in Comoros. The lowest prevalence-of pain and discomfort, poor cognition, poor vision, and poor sleep - is found in Burkina Faso, Zambia, Kenya, and Malawi, respectively, while for the four other functional domains, the lowest prevalence is observed in Mauritius.

Table 1. Prevalence of poor functional health across functional domains among adults aged 18 and older in eighteen countries in sub-Saharan Africa, WHS 2002-04

\begin{tabular}{|c|c|c|c|c|c|c|c|c|c|c|c|c|c|c|c|c|}
\hline \multirow{2}{*}{ Country } & \multicolumn{2}{|c|}{$\begin{array}{c}\text { Poor } \\
\text { mobility }\end{array}$} & \multicolumn{2}{|c|}{$\begin{array}{c}\text { Poor } \\
\text { self-care }\end{array}$} & \multicolumn{2}{|c|}{$\begin{array}{l}\text { Pain and } \\
\text { discomfort }\end{array}$} & \multicolumn{2}{|c|}{$\begin{array}{c}\text { Poor } \\
\text { cognition }\end{array}$} & \multicolumn{2}{|c|}{$\begin{array}{l}\text { Activity } \\
\text { limitation }\end{array}$} & \multicolumn{2}{|c|}{$\begin{array}{c}\text { Poor } \\
\text { vision }\end{array}$} & \multicolumn{2}{|c|}{$\begin{array}{l}\text { Poor } \\
\text { sleep }\end{array}$} & \multicolumn{2}{|c|}{$\begin{array}{l}\text { Poor } \\
\text { affect }\end{array}$} \\
\hline & $N$ & $\%$ & $N$ & $\%$ & $N$ & $\%$ & $N$ & $\%$ & $N$ & $\%$ & $N$ & $\%$ & $N$ & $\%$ & $N$ & $\%$ \\
\hline urkina Faso & 4,815 & 11.3 & 4,815 & 4.7 & 4,813 & 19.3 & 4,782 & 12.6 & 4,813 & 4.8 & 4,811 & 9.0 & 4,813 & 15.1 & 4,794 & 19.6 \\
\hline Chad & 4,617 & 20.0 & 4,612 & 10.9 & 4,613 & 25.9 & 4,582 & 18.4 & 4,581 & 10.1 & 4,402 & 14.7 & 4,597 & 18.7 & 4,586 & 21.7 \\
\hline omoros & 1,757 & 42.3 & 1,758 & 22.5 & 1,758 & 59.5 & 1,756 & 39.5 & 1,756 & 22.7 & 1,717 & 28.9 & 1,757 & 44.5 & 1,754 & 50.1 \\
\hline Congo & 2,231 & 25.4 & 2,231 & 16.3 & 2,233 & 30.3 & 2,209 & 21.6 & 2,217 & 18.6 & 2,123 & 15.5 & 2,208 & 21.8 & 2,213 & 25.9 \\
\hline ôte d'Ivoire & 3,129 & 17.3 & 3,127 & 9.3 & 3,134 & 30.3 & 3,103 & 16.6 & 3,128 & 10.3 & 3,036 & 13.2 & 3,124 & 19.0 & 3,125 & 25.0 \\
\hline Ethiopia & 4,929 & 13.0 & 4,923 & 10.5 & 4,928 & 21.5 & 4,927 & 16.5 & 4,928 & 8.1 & 4,439 & 10.8 & 4,926 & 17.3 & 4,928 & 17.8 \\
\hline Ghana & 3,921 & 12.7 & 3,924 & 5.1 & 3,925 & 28.2 & 3,926 & 17.1 & 3,916 & 7.9 & 3,907 & 12.8 & 3,921 & 17.3 & 3,925 & 18.4 \\
\hline enya & 4,339 & 12.2 & 4,340 & 4.3 & 4,339 & 22.1 & 4,340 & 13.4 & 4,337 & 7.1 & 4,337 & 8.0 & 4,338 & 17.6 & 4,339 & 19.9 \\
\hline Malawi & 5,285 & 13.3 & 5,284 & 5.9 & 5,286 & 25.2 & 5,288 & 12.8 & 5,275 & 7.5 & 5,276 & 9.7 & 5,279 & 13.1 & 5,277 & 16.9 \\
\hline Mali & 3,718 & 12.8 & 3,723 & 5.6 & 3,725 & 19.5 & 3,673 & 10.9 & 3,679 & 7.1 & 1,002 & 12.2 & 3,674 & 13.4 & 3,692 & 16.5 \\
\hline Mauritania & 3,747 & 20.2 & 3,744 & 19.9 & 3,737 & 25.9 & 3,727 & 24.1 & 3,733 & 15.1 & 3,625 & 21.3 & 3,734 & 19.7 & 3,726 & 18.0 \\
\hline Mauritius & 3,886 & 9.5 & 3,886 & 4.2 & 3,886 & 22.0 & 3,887 & 13.0 & 3,880 & 3.3 & 3,817 & 9.4 & 3,882 & 16.7 & 3,879 & 13.5 \\
\hline Namibia & 3,982 & 17.2 & 3,985 & 13.0 & 3,982 & 25.5 & 3,984 & 16.0 & 3,902 & 29.6 & 3,541 & 16.5, & 3,980 & 20.4 & 3,976 & 21.0 \\
\hline Senegal & 2,806 & 18.1 & 2,814 & 7.9 & 2,814 & 26.6 & 2,795 & 16.4 & 2,807 & 9.7 & 2,511 & 14.7 & 2,794 & 22.9 & 2,800 & 24.0 \\
\hline South Africa & 2,343 & 14.7 & 2,340 & 9.3 & 2,340 & 28.5 & 2,329 & 19.0 & 2,334 & 14.9 & 2,030 & 15.5 & 2,336 & 22.7 & 2,332 & 25.6 \\
\hline waziland & 2,066 & 30.7 & 2,060 & 16.3 & 2,062 & 40.9 & 2,059 & 26.8 & 2,061 & 18.4 & 2,038 & 26.1 & 2,063 & 37.6 & 2,061 & 38.0 \\
\hline Zambia & 3,810 & 11.8 & 3,808 & 5.7 & 3,807 & 20.4 & 3,807 & 10.8 & 3,804 & 10.0 & 3,393 & 13.1 & 3,806 & 12.7 & 3,806 & 20.3 \\
\hline Zimbabwe & 4,014 & 14.6 & 4,023 & 6.3 & 4,021 & 28.9 & 4,020 & 17.3 & 4,013 & 6.6 & 4,013 & 14.1 & 4,019 & 25.6 & 4,017 & 23.4 \\
\hline All countries & 65,396 & 13.8 & 65,397 & 8.0 & 65,403 & 24.3 & 65,194 & 15.7 & 65,164 & 9.6 & 60,018 & 12.2 & 65,251 & 18.2 & 65,230 & 20.7 \\
\hline
\end{tabular}

Note: All data are weighted using sampling weights which reflect each country's population distribution.

\section{Educational differences in poor functional health}

Table 2 shows the bivariate relationships between education and each of the eight functional domains. As might be expected, poor functional health is more prevalent in individuals without education than in more highly educated persons. For all functional domains (except for affect), a descending gradient in the prevalence of poor functional health is observed, running from to the lowest to the highest educated individuals (Table 2). Most striking are educational differences in self-care, where poor health is about three times as high in persons with no education (12.1 per cent) as in more highly educated persons (4.1 per cent). Poor functional health is over two times as high in uneducated individuals as in more highly educated individuals in mobility (19.2 vs. 8.5 per cent), cognition (20.5 vs. 9.7 per cent), and vision (17.4 vs. 7.4 per cent).

Table 3 presents the results of the logistic regression models for poor functional health across functional domains by education level, controlling for socio-demographic factors. We find that there is a significant decrease in the odds of poor functional health with increasing education level. Educational inequalities in health (i.e., to the detriment of individuals without education) are consistently statistically significant for all the func- 
Table 2. Prevalence of poor functional health across functional domains among adults aged 18 and older by education; pooled analysis of eighteen countries in sub-Saharan Africa, WHS 2002-04

\begin{tabular}{|c|c|c|c|c|c|c|}
\hline \multirow{2}{*}{$\begin{array}{l}\text { Disability } \\
\text { measures }(\%)\end{array}$} & \multicolumn{4}{|c|}{ Education } & \multirow{2}{*}{$p$ value $^{\mathrm{a}}$} & \multirow{2}{*}{$N$} \\
\hline & none & primary & secondary & high & & \\
\hline Poor mobility & 19.2 & 12.8 & 8.8 & 8.5 & $p<.001$ & 65,257 \\
\hline Poor self-care & 12.1 & 6.6 & 5.6 & 4.1 & $p<.001$ & 65,257 \\
\hline Pain & 30.5 & 23.9 & 17.2 & 18.0 & $p<.001$ & 65,263 \\
\hline Poor cognition & 20.5 & 14.9 & 12.4 & 9.7 & $p<.001$ & 65,055 \\
\hline Activity limitation & 11.1 & 8.9 & 9.1 & 8.6 & $p<.001$ & 65,025 \\
\hline Poor vision & 17.4 & 11.4 & 7.9 & 7.4 & $p<.001$ & 59,896 \\
\hline Poor sleep & 22.7 & 17.5 & 14.3 & 13.6 & $p<.001$ & 65,114 \\
\hline Poor affect & 22.9 & 20.4 & 17.7 & 19.6 & $p<.001$ & 65,091 \\
\hline
\end{tabular}

Note: All data are weighted using sampling weights which reflect each country's population distribution.

${ }^{a} p$ value is based on Chi-squared test.

Table 3. Odds ratios ( $95 \%$ confidence intervals) for poor functional health across functional domains among adults aged 18 and older by education; pooled analysis of eighteen countries in sub-Saharan Africa, WHS 2002-04

\begin{tabular}{lcccccccc}
\hline Education & $\begin{array}{c}\text { Poor } \\
\text { mobility }\end{array}$ & $\begin{array}{c}\text { Poor } \\
\text { self-care }\end{array}$ & $\begin{array}{c}\text { Pain and } \\
\text { discomfort }\end{array}$ & $\begin{array}{c}\text { Poor } \\
\text { cognition }\end{array}$ & $\begin{array}{c}\text { Activity } \\
\text { limitation }\end{array}$ & $\begin{array}{c}\text { Poor } \\
\text { vision }\end{array}$ & $\begin{array}{c}\text { Poor } \\
\text { sleep }\end{array}$ & $\begin{array}{c}\text { Poor } \\
\text { affect }\end{array}$ \\
\hline $\begin{array}{l}\text { None } \\
\text { Primary }\end{array}$ & $0.87 *$ & $0.78 * *$ & $0.85 * * *$ & $0.89 *$ & $0.88^{* *}$ & $0.88 * * *$ & $0.82 * * *$ & 0.96 \\
& $(0.78-0.98)$ & $(0.67-0.91)$ & $(0.77-0.93)$ & $(0.79-0.99)$ & $(0.82-0.94)$ & $(0.82-0.94)$ & $(0.74-0.91)$ & $(0.87-1.06)$ \\
Secondary & $0.70 * * *$ & $0.69 *$ & $0.68 * * *$ & $0.77 * *$ & $0.79 * * *$ & $0.77 * * *$ & $0.68 * * *$ & 0.89 \\
& $(0.58-0.84)$ & $(0.52-0.92)$ & $(0.58-0.79)$ & $(0.65-0.92)$ & $(0.71-0.88)$ & $(0.69-0.85)$ & $(0.57-0.80)$ & $(0.76-1.03)$ \\
High & $0.59 * * *$ & $0.46 * * *$ & $0.59 * * *$ & $0.52 * * *$ & $0.72 * * *$ & $0.72 * * *$ & $0.55 * * *$ & 0.86 \\
& $(0.46-0.76)$ & $(0.34-0.62)$ & $(0.50-0.71)$ & $(0.41-0.65)$ & $(0.64-0.81)$ & $(0.63-0.81)$ & $(0.45-0.67)$ & $(0.71-1.04)$ \\
\hline$N$ & 64,338 & 64,338 & 64,342 & 64,147 & 64,339 & 59,422 & 64,207 & 64,181 \\
\hline
\end{tabular}

Notes: All data are weighted using sampling weights which reflect each country's population distribution. All models are adjusted for sex, age, marital status, place of residence, and country-fixed effects.

${ }^{a}$ Reference category.

$* p<.05 ; * * p<.01 ; * * * p<.001$

tional domains considered (except for affect), after adjusting for age, sex, marital status, place, and country of residence. However, the size of these inequalities vary across the functional domains. Indeed, the odds of both poor self-care and cognition were estimated to be about twice as high for individuals with no education as for more highly educated individuals. For the other functional domains (except for interpersonal activities and sleep), the odds of poor functional health are estimated to be over one and one-half times as high for uneducated persons as for more highly educated persons.

To test sensitivity, we repeat the analysis in Table 4 without treating education as a categorical variable but instead using the number of years of schooling in the logistic regression models. The patterns of association between number of years of schooling and poor functional health remain the same, and mirror the results using education as a categorical variable. For all the functional domains considered (except for affect), there is a negative association between number of years of schooling and poor functional health (see Table 4).

\section{Association between education and poor functional health by age group}

The analyses of the association between education and poor functional health by age group are depicted in Table 4. The results show that the negative association between the number of years of schooling and poor functional health is observed for almost all of the functional domains considered, even though the relationship does not always attain conventional levels of statistical significance (see Table 4). 
Onadja et al.: Socio-economic differences in disability by age in sub-Saharan Africa

Table 4. Odds ratios ( $95 \%$ confidence intervals) reflecting the change in the odds of poor functional health with every oneyear increase in schooling, in eighteen countries in sub-Saharan Africa by age group, WHS 2002-2004

\begin{tabular}{|c|c|c|c|c|c|c|c|c|}
\hline $\begin{array}{l}\text { Age and } \\
\text { education }\end{array}$ & $\begin{array}{c}\text { Poor } \\
\text { mobility }\end{array}$ & $\begin{array}{c}\text { Poor } \\
\text { self-care }\end{array}$ & $\begin{array}{c}\text { Pain and } \\
\text { discomfort }\end{array}$ & $\begin{array}{c}\text { Poor } \\
\text { cognition }\end{array}$ & $\begin{array}{c}\text { Activity } \\
\text { limitation }\end{array}$ & $\begin{array}{l}\text { Poor } \\
\text { vision }\end{array}$ & $\begin{array}{l}\text { Poor } \\
\text { sleep }\end{array}$ & $\begin{array}{l}\text { Poor } \\
\text { affect }\end{array}$ \\
\hline \multicolumn{9}{|l|}{ All age groups } \\
\hline $\begin{array}{r}\text { Years of } \\
\text { schooling }\end{array}$ & $\begin{array}{l}0.97 * * * \\
(0.95-0.98)\end{array}$ & $\begin{array}{l}0.96 * * * \\
(0.94-0.97)\end{array}$ & $\begin{array}{l}0.97 * * * \\
(0.96-0.98)\end{array}$ & $\begin{array}{l}0.97 * * * \\
(0.96-0.98)\end{array}$ & $\begin{array}{l}0.98^{*} \\
(0.97-1.00)\end{array}$ & $\begin{array}{l}0.97 * * * \\
(0.95-0.98)\end{array}$ & $\begin{array}{l}0.97 * * * \\
(0.96-0.98)\end{array}$ & $\begin{array}{l}0.99 \dagger \\
(0.98-1.00)\end{array}$ \\
\hline \multicolumn{9}{|l|}{$18-29$ yrs. } \\
\hline $\begin{array}{r}\text { Years of } \\
\text { schooling }\end{array}$ & $\begin{array}{l}0.98 \dagger \\
(0.96-1.00)\end{array}$ & $\begin{array}{l}0.97 \dagger \\
(0.94-1.00)\end{array}$ & $\begin{array}{l}0.99 \\
(0.97-1.01)\end{array}$ & $\begin{array}{l}0.98^{*} \\
(0.96-1.00)\end{array}$ & $\begin{array}{l}1.01 \\
(0.98-1.04)\end{array}$ & $\begin{array}{l}0.97 \\
(0.94-1.01)\end{array}$ & $\begin{array}{l}0.98 \dagger \\
(0.96-1.00)\end{array}$ & $\begin{array}{l}0.99 \\
(0.97-1.01)\end{array}$ \\
\hline \multicolumn{9}{|c|}{ 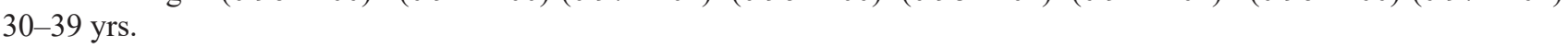 } \\
\hline $\begin{array}{r}\text { Years of } \\
\text { schooling }\end{array}$ & $\begin{array}{l}0.99 \\
(0.97-1.02)\end{array}$ & $\begin{array}{l}0.98 \\
(0.95-1.01)\end{array}$ & $\begin{array}{l}0.97 * \\
(0.96-0.99)\end{array}$ & $\begin{array}{l}0.98^{*} \\
(0.96-1.00)\end{array}$ & $\begin{array}{l}0.99 \\
(0.96-1.01)\end{array}$ & $\begin{array}{l}0.98 \\
(0.94-0.99)\end{array}$ & $\begin{array}{l}0.98 \dagger \\
(0.96-1.00)\end{array}$ & $\begin{array}{l}0.99 \\
(0.97-1.01)\end{array}$ \\
\hline \multicolumn{9}{|l|}{ 40-49 yrs. } \\
\hline $\begin{array}{r}\text { Years of } \\
\text { schooling }\end{array}$ & $\begin{array}{l}0.97 \dagger \\
(0.95-1.00)\end{array}$ & $\begin{array}{l}0.95 * \\
(0.92-0.99)\end{array}$ & $\begin{array}{l}0.96 * * * \\
(0.94-0.98)\end{array}$ & $\begin{array}{l}0.98 \\
(0.96-1.01)\end{array}$ & $\begin{array}{l}0.99 \\
(0.96-1.02)\end{array}$ & $\begin{array}{l}0.96 * * \\
(0.94-0.99)\end{array}$ & $\begin{array}{l}0.97 * * \\
(0.94-0.99)\end{array}$ & $\begin{array}{l}0.98 \dagger \\
(0.96-1.00)\end{array}$ \\
\hline \multicolumn{9}{|l|}{ 50-59 yrs. } \\
\hline $\begin{array}{r}\text { Years of } \\
\text { schooling }\end{array}$ & $(0.91-0.99)$ & $\begin{array}{l}0.96 \dagger \\
(0.92-1.00)\end{array}$ & $\begin{array}{l}0.94 * * * \\
(0.91-0.97)\end{array}$ & $\begin{array}{l}0.96 \\
(0.92-1.01)\end{array}$ & $\begin{array}{l}0.94^{*} \\
(0.90-0.99)\end{array}$ & $\begin{array}{l}0.98 \\
(0.95-1.01)\end{array}$ & $\begin{array}{l}0.97 \dagger \\
(0.93-1.00)\end{array}$ & $\begin{array}{l}1.02 \\
(0.98-1.06)\end{array}$ \\
\hline Yea & $0.90 * * *$ & $0.86^{* * *}$ & $0.92 * * *$ & $0.90 * * *$ & $0.89 * * *$ & $0.94 * *$ & $0.93^{*}$ & \\
\hline $\begin{array}{l}\text { schooling } \\
0+\text { yrs. }\end{array}$ & $(0.86-0.94)$ & $(0.81-0.92)$ & $(0.89-0.96)$ & $(0.86-0.95)$ & $(0.85-0.94)$ & $(0.91-0.99)$ & $(0.89-0.97)$ & $(0.88-0.95)$ \\
\hline $\begin{array}{r}\text { Years of } \\
\text { schooling }\end{array}$ & $\begin{array}{l}0.98 \\
(0.93-1.03)\end{array}$ & $\begin{array}{l}0.97 \\
(0.90-1.05)\end{array}$ & $\begin{array}{l}0.96 \\
(0.91-1.01)\end{array}$ & $\begin{array}{l}0.99 \\
(0.94-1.05)\end{array}$ & $\begin{array}{l}0.95 \dagger \\
(0.90-1.0\end{array}$ & $\begin{array}{l}0.97 \\
(0.92-1.02)\end{array}$ & $\begin{array}{l}0.98 \\
(0.93-1.03)\end{array}$ & $\begin{array}{l}1.01 \\
(0.96-1.07)\end{array}$ \\
\hline
\end{tabular}

Notes: All data are weighted using sampling weights which reflect each country's population distribution. All models are adjusted for sex, age, marital status, place of residence, and country-fixed effects.

$\dagger p<.10 ; * p<.05 ; * * p<.01 ; * * * p<.001$

Figure 1 complements the above findings by presenting the predicted probability of poor functional health for the lowest- and highest-educated persons across age groups for pooled data, while holding constant all socio-demographic factors. We see that the predicted probability of poor functional health increases across age groups for these two educational levels, and this pattern of findings is observed for all the eight functional domains considered (Figure 1a, b, c, d, e, f, g, and h). For all the functional domains considered (except for affect), the predicted probability of poor health is higher among individuals without education at any age group, and the differences between these two educational groups are statistically significant in each age group, as illustrated by the non-overlap between the 95-per-cent confidence intervals. Furthermore, the dominant feature of all the charts depicted in Figure 1 seems to indicate an increasing functional health gap between these two educational groups across age groups. Therefore, this visual inspection of the functional health patterns lends some support to the plausibility of the cumulative advantage hypothesis.

\section{Discussion}

This study aims to examine the relationship between SES and disability among adults in sub-Saharan Africa and to determine whether the strength of this relationship varies across multiple age groups. The analyses use a cross-national sample of adults aged 18 years and older from eighteen sub-Saharan African countries that have participated in the WHS, as well as multiple measures of disability and educational as the key indicator of SES.

The results indicate that there is a significant decrease in poor functional health with increasing education level, and this decrease is observed in all the functional domains (except for affect). These findings are consistent with recent research in low- and middle-income countries reporting positive associations between low education level and poor health outcomes (Hosseinpoor et al. 2013). A recent multi-country study of forty-one low-income countries (including the sub-Saharan African countries considered in this study) finds that low education levels are positively associated with an increased probability of having a chronic disease (such as angina, 
(a) Mobility

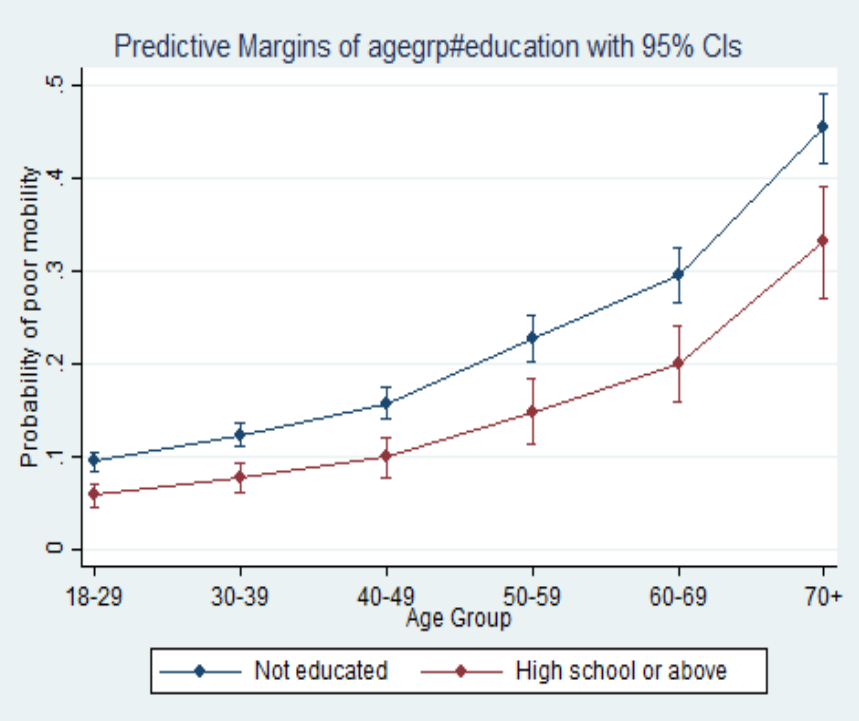

(c) Pain

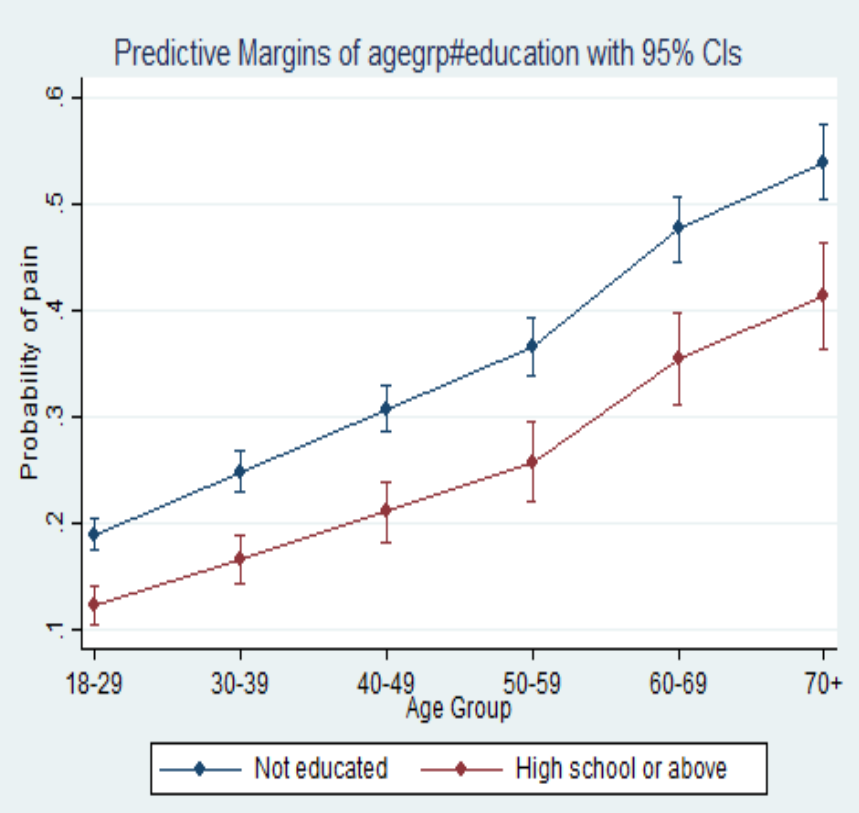

(b) Self-care

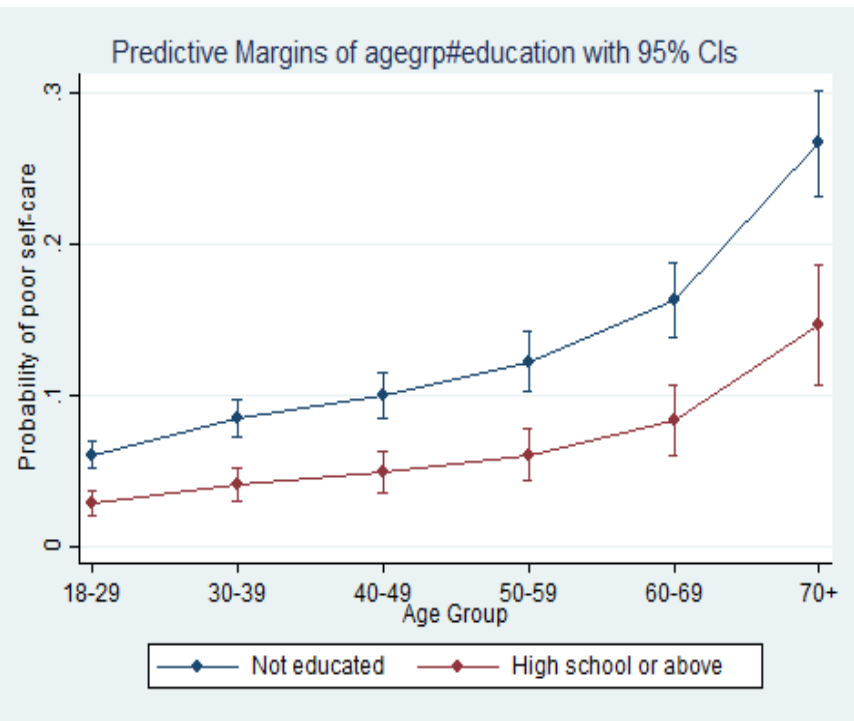

(d) Cognition

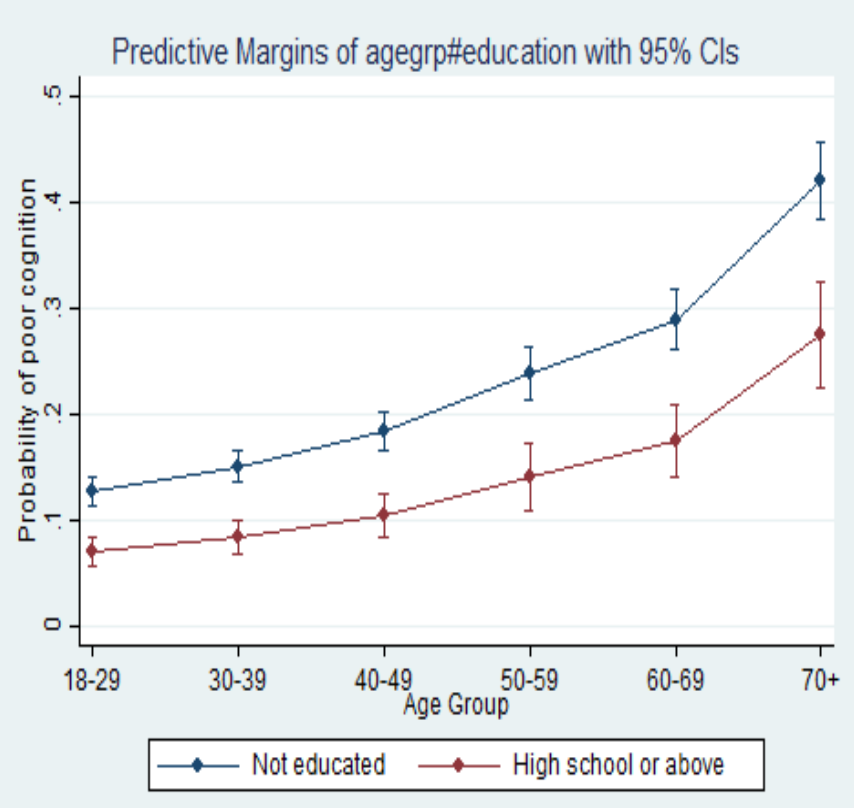

Figure 1. Predicted probability of poor functional health for the lowest versus the highest educated adults across functional domains by age group; pooled analysis of eighteen countries in sub-Saharan Africa, WHS $2002-04$.

arthritis, and asthma) and elevated numbers of chronic diseases (Hosseinpoor et al. 2012a), which in turn may significantly lower physical, social, and mental well-being (Fortin et al. 2004). As indicated by previous research, three general classes of factors are supposed as potential mediators of the relationship between education and health outcomes: economic factors, psychosocial factors, and health knowledge and behavioural factors (Ross and Wu 1995). For example, people with lower education have fewer economic resources (such as income and occupation) to purchase preventive and therapeutic health care as well as health insurance coverage (Herd et al. 2007). Furthermore, less-educated persons have fewer psychosocial resources such as coping resources and strategies, social support, problem-solving skills, and cognitive abilities to avoid the consequences of stress (Ross and Wu 1995). Poorly educated persons may also have more exposure to chronic stressors (such as re- 
(e) Activity limitation

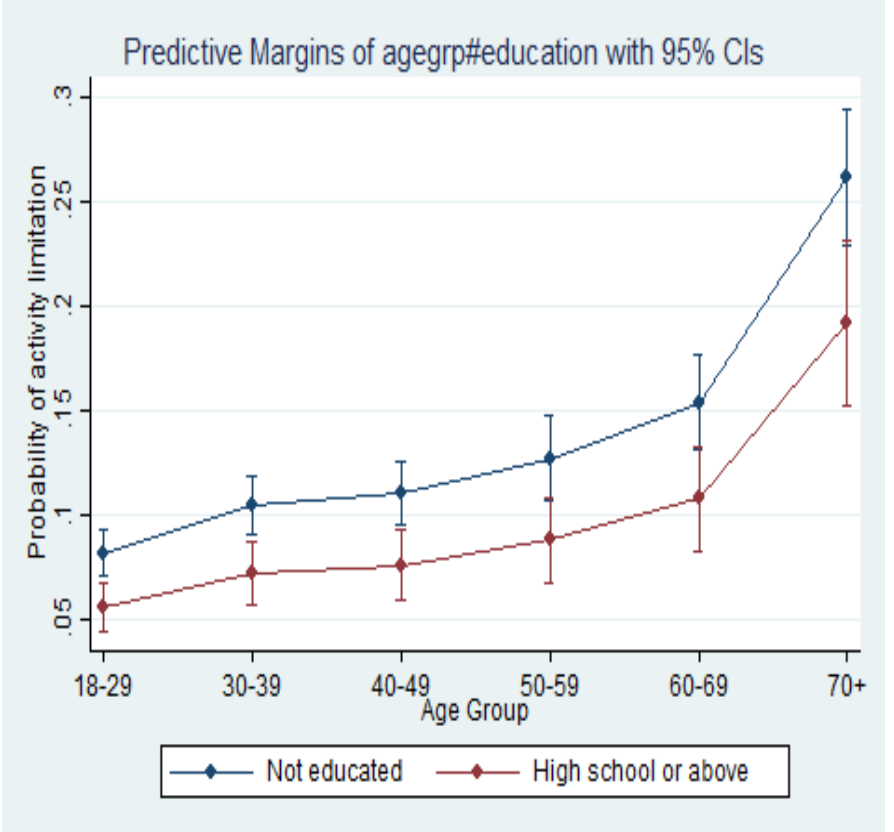

(f) Vision

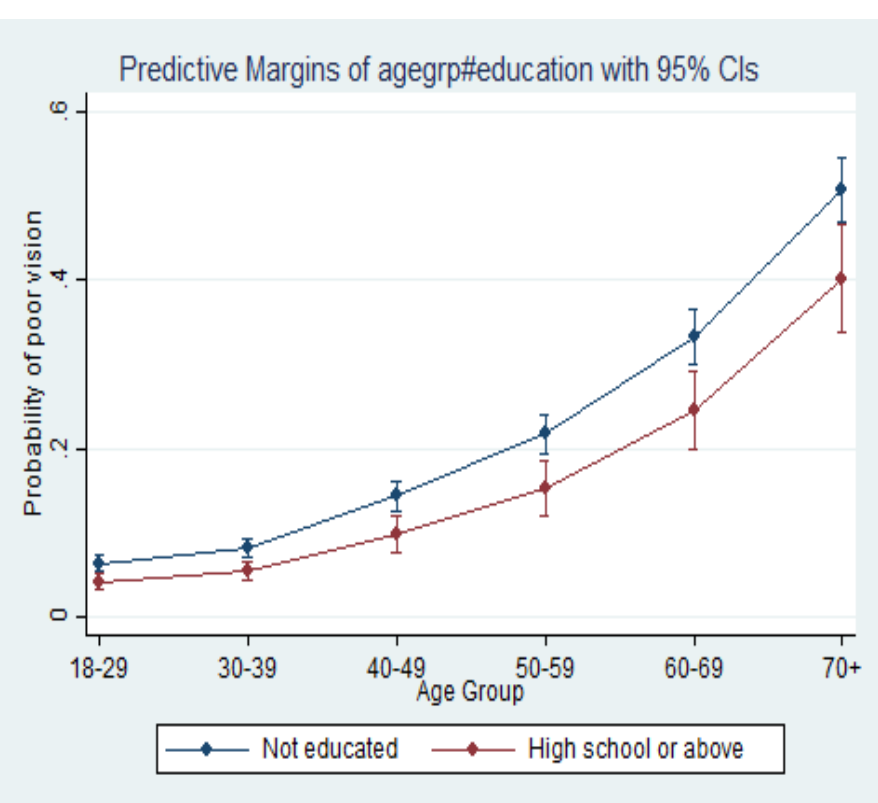

(h) Affect

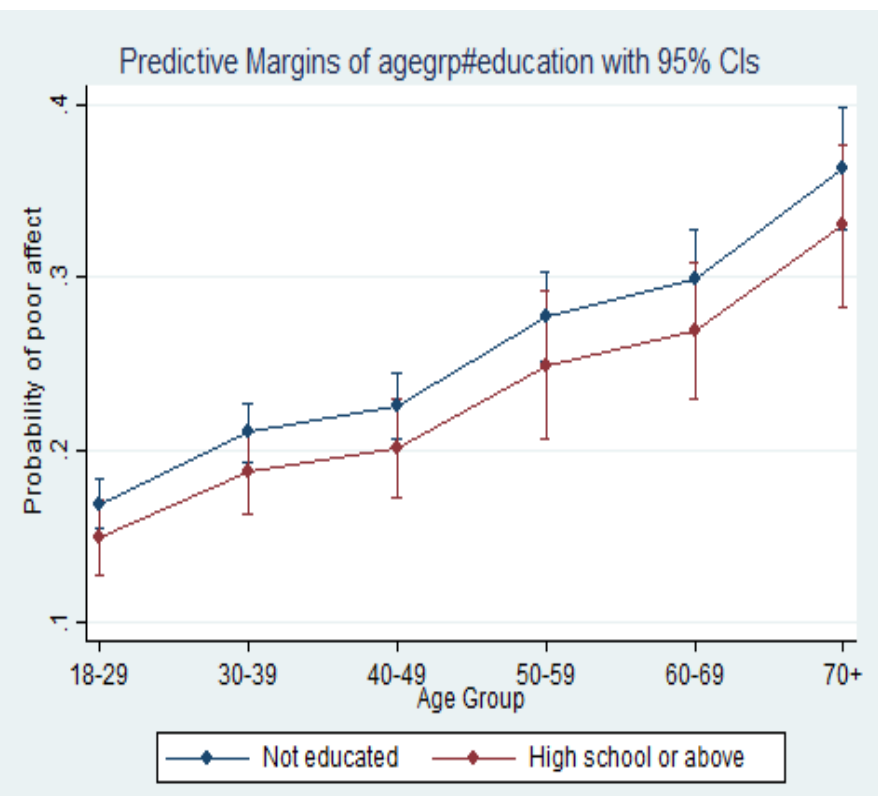

Figure 1 (cont'd). Predicted probability of poor functional health for the lowest versus the highest educated adults across functional domains by age group; pooled analysis of eighteen countries in sub-Saharan Africa, WHS 2002-04.

lationship and family problems, financial stress) and negative life events (Lantz et al. 2005; Turner et al. 1995), and the less educated are less likely to engage in health-promoting behaviours, including good nutrition, physical activity, utilization of preventive and therapeutic health care, and abstaining from smoking (Mirowsky and Ross 2003). Such educational differences in economic and social resources as well as in health-promoting behaviours (i.e., those to the detriment of individuals with lower education) can significantly contribute to disadvantages for the under-educated in functional health. 
Our study shows that the functional health gap between educational levels increases between age groups, and this pattern of findings is observed for almost all of the eight functional domains considered. Our findings agree with many studies conducted in the United States supporting the cumulative advantage hypothesis (Lynch 2003; Ross and Wu 1996; Willson et al. 2007), but are different from those of some American and European studies that report either the age-as-leveller hypothesis (Herd 2006; House et al. 1994) or the maintenance status hypothesis (Schöllgen et al. 2010). There could be important differences between countries in the development of socio-economic inequalities in health because of different social welfare policies between age groups, as well as differences in the extent of socio-economic inequalities specific at each age group. For example, studies that report a constant health gap by education level across age suggest the importance of a strong welfare state (Schöllgen et al. 2010). In Northern and Western European countries, including Germany, wealth is distributed more equally than in the US (von dem Knesebeck et al. 2003; Schöllgen et al. 2010), and thus it is likely that the relatively high levels of social justice in these countries provide enough resources throughout the life course so that there is little accumulation of disadvantage and little selection mortality. Under these circumstances, the role of parental SES and early life conditions may be the main determinants of health at the different stages of the life course. On the contrary, in unfair countries such as the US, disadvantages will accumulate over the life course and there will be both a cumulative disadvantage and age-as-leveller at play. This is evident with the crossover patterns of mortality observed between Blacks and Whites in the US. Blacks have higher levels of mortality than Whites throughout their life span until an advanced age, when they start having lower levels than Whites due to the selective survival of more hardy Blacks (Markides and Machalek 1984).

As indicated above, our study reveals an increasing functional health gap between educational levels by age groups. A plausible hypothesis to explain the increasing educational health differences across age groups in subSaharan Africa may be the age differences in the distribution of economic, psychosocial, and behavioural factors that mediate the relationship between education and functional health. Indeed, most sub-Saharan African societies invest more heavily in improving the social, economic, and health-care status of children and younger adults as compared to the older population (National Research Council 2006). These social welfare policies, as well as limited access to other productive assets and savings, are likely to exacerbate poverty and deprivation among the elderly, and hence may increase educational differences in exposure to psychosocial risk factors in older age.

Certain limitations of the present study should be noted. First, because our data are cross-sectional, it is possible that the educational inequalities in functional health across age groups presented here are influenced by cohort effects. Indeed, it is often difficult in cross-sectional studies such as this one to isolate the effects of age and cohort. Secondly, our study faces the problems of endogeneity of education, as both education and health could be associated with unobserved factors such as inherent cognitive ability (or general intelligence) (Gottfredson 2004; Gottfredson and Deary 2004). Because of possible omitted relevant variables (such as inherent cognitive ability or general intelligence), it is unclear whether the association of education with multiple disability measures found in this paper can be taken as a causal effect of education. However, some recent studies use appropriate methodologies (such as instrumental variables strategies and regression discontinuity designs) to isolate the part of education that is independent of unobserved factors affecting health, and show a significant causal effect of education on health outcomes (Banks and Mazzonna 2012; Glymour et al. 2008; Lleras-Muney 2005; Oreopoulos 2006). Third, the use of pooled data may mask important differences between countries. However, as noted above, we use country-fixed effects logistic models to control for this unobserved betweencountry heterogeneity and to therefore obtain consistent estimates of the within-country relationship between education and disability measures. Furthermore, the large sample used in this study makes it possible for us to obtain precise estimates of the educational differences in health outcomes at each age group.

In spite of the methodological problems raised above, the findings produced in the present study using the 2002-04 WHS cross-sectionally comparable data may be interpreted with confidence, and provide a first step toward understanding the SES-health relationship across age groups in sub-Saharan African countries. The increasing educational differences in functional health across age groups observed here suggest that in subSaharan African countries, compared with people with higher education, the under-educated are less successful in postponing disability to later ages. 


\section{Acknowledgements}

The authors wish to thank the World Health Organization for providing access to the dataset.

\section{References}

Adler, N.E., T. Boyce, M.A. Chesney, S. Cohen, S. Folkman, R.L. Kahn, and S.L. Syme. 1994. Socioeconomic status and health: The challenge of the gradient. American Psychologist 49(1):15-24.

Alvares, J.L., R. Gil, V. Hernandez, and A. Gil. 2009. Factors associated with maternal mortality in sub-Saharan Africa: An ecological study. BMC Public Health 9:462, https://doi.org/10.1186/1471-2458-9-462.

Aneshensel, C.S., R.R. Frerichs, and G.J. Huba. 1984. Depression and physical illness: A multiwave, nonrecursive causal model. Journal of Health and Social Behavior 25(4):350-71.

Banks, J., and F. Mazzonna. 2012. The effect of education on old age cognitive abilities: Evidence from a regression discontinuity design. Economic Journal 122(560):418-48.

Beckett, M. 2000. Converging health inequalities in later life: An artifact of mortality selection? Journal of Health and Social Behavior 41(1):106-19.

Beydoun, M.A. and B.M. Popkin. 2005. The impact of socio-economic factors on functional status decline among community-dwelling older adults in China. Social Science and Medicine 60(9):2045-57.

Caldwell, J.C. 1986. Routes to low mortaliy in poor counries. Populaion and Development Review 12(2):171-220.

Chen, F., Y. Yang, and G. Liu. 2010. Social change and socioeconomic disparities in health over the life course in China : A cohort analysis. American Sociological Review 75(1):126-50.

Corna, L.M. 2013. A life course perspective on socioeconomic inequalities in health: A critical review of conceptual frameworks. Advances in Life Course Research 18(2): 150-59.

Desai, J., and S. Alva. 1998. Maternal education and child health: Is there a strong causal relationship? Demography 35(1):71-81.

Dupre, M.E. 2007. Educational differences in age-related patterns of disease: Reconsidering the cumulative disadvantage and age-as-leveler hypotheses. Journal of Health and Social Behavior 48(1):1-15.

Eikemo, T.A., M. Huisman, C. Bambra, and A.E. Kunst. 2008. Health inequalities according to educational level in different welfare regimes: A comparison of 23 European countries. Sociology of Health \& Illness 30(4):565-82.

Elo, I.T., and S.H. Preston. 1996. Educational differentials in mortality: United States 1970-85. Social Science \& Medicine 42(1):47-57.

Feinstein, J.S. 1993. The relationship between socioeconomic status and health. Milbank Quarterly 71(2):279-322.

Ferguson, B., A. Tandon, E. Gakidou, and C.J.L. Murray. 2003. Estimating permanent income using asset and indicator variables, in Health Systems Performance Assessment: Debates, Methods and Empiricism, edited by C.J.L Murray and D.B. Evans. Geneva: World Health Organization, p. 747-60.

Fortin, M., L. Lapointe, C. Hudon, A. Vanasse, A.L. Ntetu, and D. Maltais. 2004. Multimorbidity and quality of life in primary care: A systematic review. Health and Quality of Life Outcomes 2:51, https://doi.org/10.1186/14777525-2-51.

Glymour, M.M., I. Kawachi, C.S. Jencks, and L.F. Berkman. 2008. Does childhood schooling affect old age memory or mental status? Using state schooling laws as natural experiments. Journal of Epidemiology and Community Health 62(6):532-37.

Gottfredson, L.S. 2004. Intelligence: Is it the epidemiologists" elusive "fundamental cause" of social class inequalities in health? Journal of Personality and Social Psychology 86(1):174-99. 
Gottfredson, L.S., and I.J. Deary. 2004. Intelligence predicts health and longevity, but why? Current Directions in Psychological Science 13(1):1-4.

Herd, P. 2006. Do functional health inequalities decrease in old age? Educational status and functional decline among the 1931-1941 birth cohort. Research on Aging 28(3):375-92.

Herd, P., B. Goesling, and J.S. House. 2007. Socioeconomic position and health: The differential effects of education versus income on the onset versus progression of health problems. Journal of Health and Social Behavior 48(3):223-38.

Hosseinpoor, A.R., N. Bergen, S. Mendis, S.Harper, E. Verdes, A. Kunst, and S. Chatterji. 2012a. Socioeconomic inequality in the prevalence of noncommunicable diseases in low- and middle-income countries: Results from the World Health Survey. BMC Public Health 12:474, https://doi.org/10.1186/1471-2458-12-474.

Hosseinpoor, A.R., J.A. Stewart Williams, J. Gautam, A. Posarac, A. Officer, E. Verdes, N. Kostanjsek, and S. Chatterji. 2013. Socioeconomic inequality in disability among adults: A multicountry study using the World Health Survey. American Journal of Public Health 103(7): 1278-1286.

Hosseinpoor, A.R., J.A. Stewart Williams, L. Itani, and S. Chatterji. 2012b. Socioeconomic inequality in domains of health: Results from the World Health Surveys. BMC Public Health 12:198, https://doi.org/10.1186/1471-245812-198.

House, J.S., P.M. Lantz, and P. Herd. 2005. Continuity and change in the social stratification of aging and health over the life course: Evidence from a nationally representative longitudinal study from 1986 to 2001/2002 (Americans' Changing Lives Study). Journals of Gerontology, Series B 60(Special Issue 2):S15-S26, https:/ / doi. org/10.1093/geronb/60.Special_Issue_2.S15.

House, J.S., J.M. Lepkowski, A.M. Kinney, R.P. Mero, R.C. Kessler, and A.R. Herzog. 1994. The social stratification of aging and health. Journal of Health and Social Behavior 35(3):213-34.

Kim, J., and E. Durden. 2007. Socioeconomic status and age trajectories of health. Social Science \& Medicine 65(12):2489-502.

Kitagawa, E.M., and P.M. Hauser. 1973. Differential Mortality in the United States: A Study in Socioeconomic Epidemiology. Cambridge, MA: Harvard University Press.

Lantz, P.M., J.S. House, J.M. Lepkowski, D.R. Williams, R.P. Mero, and J. Chen. 1998. Socioeconomic factors, health behaviors, and mortality: Results from a nationally representative prospective study of US adults. Journal of the American Medical Association 279(21):1703-8.

Lantz, P.M., J.S. House, R.P. Mero, and D.R. Williams. 2005. Stress, life events, and socioeconomic disparities in health: Results from the Americans' Changing Lives Study. Journal of Health and Social Behavior 46(3):274-88.

Lauderdale, D.S. 2001. Education and survival: Birth cohort, period, and age effects. Demography 38(4):551-62.

Leopold, L., and H. Engelhartdt. 2013. Education and physical health trajectories in old age: Evidence from the Survey of Health, Ageing and Retirement in Europe (SHARE). International Journal of Public Health 58(1):23-31.

Liberatos, P., B.G. Link, and J.L. Kelsey. 1988. The measurement of social class in epidemiology. Epidemiologic Reviews 10:87-121.

Link, B.G., and J.C. Phelan. 1995. Social conditions and fundamental causes of disease. Journal of Health and Social Behavior (Extra Issue: Forty Years of Medical Sociology: The State of the Art and Directions for the Future):80-94.

Lleras-Muney, A. 2005. The relationship between education and adult mortality in the United States. Review of Economic Studies 72(1):189-221.

Lowry, D., and Y. Xie. 2009. Socioeconomic Status and Health Differentials in China: Convergence or Divergence at Older Ages? Population Studies Center Research Report 09-690. Ann Arbor: University of Michigan. 
Lynch, S.M. 2003. Cohort and life-course patterns in the relationship between education and health: A hierarchical approach. Demography 40(2):309-31.

Markides, K.S., and R. Machalek. 1984. Selective survival, aging, and society. Arcbives of Gerontology and Geriatrics 3(3):207-22.

Marmot, M.G., and R. Fuhrer. 2004. Socioeconomic position and health across midlife, in How Healthy are We? A National Study of Well-being at Midlife, edited by O.G. Brim, C.D. Ryff, and R.C. Kessler. Chicago: University of Chicago Press, p. 64-89.

Marmot, M.G., C.D. Ryff, L.L. Bumpass, M. Shipley, and N.F. Marks. 1997. Social inequalities in health: Next questions and converging evidence. Social Science \& Medicine 44(6):901-10.

Mirowsky, J., and C.E. Ross. 2003. Education, Social Status, and Health. New York: Aldine De Gruyter.

Montgomery, M.R., M. Gragnolati, K.A. Burke, and E. Paredes. 2000. Measuring living standards with proxy variables. Demography 37(2):155-74.

Moussavi, S., S. Chatterji, E. Verdes, A. Tandon, V. Patel, and B. Üstün. 2007. Depression, chronic diseases, and decrements in health: Results from the World Health Surveys. The Lancet 370(9590):851-58.

National Research Council. 2006. Aging in Sub-Saharan Africa: Recommendations for Furthering Research. Washington: National Academies Press.

Newacheck, P.W., L.H. Butler, A.K. Harper, D.L. Piontkowski, and P.E. Franks. 1980. Income and illness. Medical Care 18(12):1165-76.

O’Rand, A.M., and J.C. Henretta. 1999. Age and Inequality: Diverse Pathways Through Later Life. Boulder, CO: Westview Press.

Onadja, Y., N. Atchessi, B.A. Soura, C. Rossier, and M.V. Zunzunegui. 2013. Gender differences in cognitive impairment and mobility disability in old age: A cross-sectional study in Ouagadougou, Burkina Faso. Archives of Gerontology and Geriatrics 57(3):311-18.

Oreopoulos, P. 2006. Estimating average and local average treatment effects of education when compulsory schooling laws really matter. American Economic Review 96(1):152-75.

Power, C., and C. Hertzman. 1997. Social and biological pathways linking early life and adult disease. British Medical Bulletin 53(1):210-21.

Power, C., O. Manor, and S. Matthews. 1999. The duration and timing of exposure: Effects of socioeconomic environment on adult health. American Journal of Public Health 89(6):1059-65.

Prus, S.G. 2007. Age, SES, and health: A population level analysis of health inequalities over the life course. Sociology of Health and Illness 29(2):275-96.

Robert, S., and J.S. House. 1996. SES differentials in health by age and alternative indicators of SES. Journal of Aging and Health 8(3):359-88.

Rosero-Bixby, L., and W.H. Dow. 2009. Surprising SES gradients in mortality, health, and biomarkers in a Latin American population of adults. Journal of Gerontology: Social Sciences 64B(1):105-17.

Ross, C.E., and C Wu. 1995. The links between education and health. American Sociological Review 60(5):719-45. 1996. Education, age, and the cumulative advantage in health. Journal of Health and Social Behavior 37(1):104-20.

Rostad, B., D.J.H. Deeg, and B. Schei. 2009. Socioeconomic inequalities in health in older women. European Journal of Ageing 6(1):39-47. 
Salomon, J.A., C. Mathers, S. Chatterji, R. Sadana, and T.B. Üstün. 2003. Quantifying individual levels of health definitions, concepts and measurement issues, in Health Systems Performance Assessment: Debates, Methods and Empiricisms, edited by C.J.L Murray and D.B. Evans. Geneva: World Health Organization, p. 301-18.

Schöllgen, I., O. Huxhold, and C. Tesch-Römer. 2010. Socioeconomic status and health in the second half of life: Findings from the German Ageing Survey. European Journal of Ageing 7(1):17-28.

Smith, K.V., and N. Goldman. 2007. Socioeconomic differences in health among older adults in Mexico. Social Science \& Medicine 65(7):1372-85.

Soares, R.R. 2007. On the determinants of mortality reductions in the developing world. Population and Development Review 33(2):247-87.

Turner, R.J., B. Wheaton, and D. Lloyd. 1995. The epidemiology of social stress. American Sociological Review 60(1):104-24.

Üstün, T.B., S. Chatterji, A. Mechbal, C.J.L. Murray, and WHS Collaborating Groups. 2003. The World Health Surveys, in Health Systems Performance Assessment: Debates, Methods and Empiricism, edited by C.J.L. Murray and D.B. Evans. Geneva: World Health Organization, p. 115-26.

von dem Knesebeck, O., G. Lüschen, W.C. Cockerham, and J. Siegrist. 2003. Socioeconomic status and health among the aged in the United States and Germany: A comparative cross-sectional study. Social Science \& Medicine 57(9):1643-52.

von dem Knesebeck, O., P.E. Verde, and N. Dragano. 2006. Education and health in 22 European countries. Social Science \& Medicine 63(5):1344-51.

Willson, A.E., K.M. Shuey, and G.H. Elder, Jr. 2007. Cumulative advantage processes as mechanisms of inequality in life course health. American Journal of Sociology 112(6):1886-1924.

World Bank. 2005. World Development Report 2005. Washington, DC: World Bank.

Zimmer, Z. 2008. Poverty, wealth inequality and health among older adults in rural Cambodia. Social Science \& Medicine 66(1):57-71.

Zimmer, Z., and P. Amornsirisomboon. 2001. Socioeconomic status and health among older adults in Thailand: An examination using multiple indicators. Social Science \& Medicine 52(8):1297-1311. 